\title{
Hydraulic Performance of Drip Irrigation in Tomato - A Review
}

\author{
Satyendra Thakur ${ }^{1 *}$, S.K. Pyasi ${ }^{1}$, B.K. Yadav $^{2}$, R.N. Shrivastava ${ }^{1}$, \\ S.K. Sharma ${ }^{4}$ and R.B. Singh ${ }^{1}$ \\ ${ }^{1}$ Department of Soil and Water Engineering, College of Agricultural Engineering, JNKVV, \\ Jabalpur, (M.P.), India \\ ${ }^{3}$ Jain Irrigation Systems Ltd, Jain Hills, Jalgaon, Maharashtra, India \\ ${ }^{5}$ Department of Mathematics, CAE, JNKVV, Jabalpur, (M.P.), India \\ *Corresponding author
}

\section{A B S T R A C T}

\section{Keywords}

Drip irrigation, Hydraulic performance, Economics

Article Info

Accepted:

16 April 2018

Available Online:

10 May 2018
The conventional method of Tomato cultivation under furrow irrigation needs a paradigm shift towards modern irrigation systems due to water scarcity. Drip irrigation method distributes water to the field using the pipe network and transforms it from the pipe network of the plant by emitters. In spite of the advantages of drip irrigation method, the traditional network of drip irrigation method has many problems. Hydraulic design seems to be only one of the minor factors of the evaluation of overall uniformity of a micro-irrigation system. However hydraulic performance of drip irrigation needs to be gauged in terms of water distribution uniformity, emitter operating pressure head, distribution uniformity of water soluble fertilizer and Economics of drip systems.

\section{Introduction}

Water in these regions is the most limiting factor requiring its optimal use. Irrigation water is supplied to the plants/crops to replenish root-zone moisture storage when natural rainfall is inadequate or poorly distributed. The efficient utilization of irrigation water is possible by the adoption of high efficient irrigation system, such as, drip irrigation systems. Drip irrigation method is the best method that has been used in the world among the other irrigation methods because of its good and high uniformity. Drip irrigation system can apply frequent and small amounts of irrigation water at many points of a field surface/subsurface near the plants (Decroix and Malaval, 1985; Youngs et al., 1999). With drip irrigation, plant water and fertilizer requirements can also be applied to the plant root zone with minimum losses, maintaining steady moisture in the soil profile. In addition, drip irrigation system has the advantage of fitting to difficult topography (Wei et al., 2003). Drip irrigation has advantages over conventional furrow 
irrigation as an efficient means of applying water, especially where water is limited (Camp, 1989).

Tomato (lycopersicum esculentum) is edible, belongs to the family Solanaceae. It is an herbaceous annual plant with bisexual flowers. The fruit is a true berry. Tomato is a warm season crop, it requires warm and cool climate. The plant cannot with stand frost and high humidity. Also light intensity affect pigmentation, fruit colour, fruit set. Tomato does very well on most mineral soils, but they prefer deep, well drained sandy loams. Tomato is a moderately tolerant cop to a wide $\mathrm{pH}$ range. A $\mathrm{pH}$ 5.5-6.8 is preferred. Soils extremely high in organic matter are not recommended due to the high moisture content of this media and nutrient deficiencies.

Tomato is considered as one of the important commercial vegetable crops grown in India. The total land area under cultivation of this crop was 458.1 thousand ha during 2001-02 and the area increased to 808.5 thousand ha within a span of 17 years. Productivity level of tomato in the country is $24.4 \mathrm{MT} / \mathrm{ha}$, and production 19696.9 thousand MT (Horticulture at glance 2017).

Some studies have shown that higher tomatoes yields are obtained by drip irrigation compared to other irrigation methods.

Tekinel et al., (1989) compared drip irrigation and conventional irrigation methods for tomatoes in the Cukurova Region in Turkey and obtained the highest yield and water use effi ciency (WUE) with drip irrigation.

Jadhaw et al., (1990) tested drip and furrow methods for tomatoes. Tomatoes yields were 48 t ha-1 for drip irrigation systems with pressure-compensating emitters and $32 \mathrm{t} \mathrm{ha}^{-1}$ when furrow irrigation was used.
Kadam (1993) compared the effects of furrow, sprinkler and drip irrigation methods on the growth of tomatoes and drip irrigation resulted in the highest plant leaf area and fruit yields.

\section{Hydraulics of Drip Irrigation}

There have been many studies on the hydraulics of drip irrigation systems. These studies have commented on the methods and parameters used for micro-irrigation system design.

Watters and Keller (1978) reported that the Darcy-Weisbach equation was employed for calculating the head loss due to friction in the trickle irrigation system as the drip pipes were assumed to be hydraulically smooth.

Kang and Nishiyama (1994) developed a polynomial expression for the inlet discharge and the inlet pressure head and used to design the drip irrigation system.

Bagarello et al., (1997) proposed a procedure for evaluating local losses caused by the emitter barb (for those emitters that have barbs) by characterizing pipe-emitter system with an obstruction index. They showed that the loss depends not only on the emitter geometry, but also on the emitter connection and deformation of the pipe around the stem.

Singh (1999) listed and described various standardized specifications and details of laterals, emitting pipes, micro-tubes, emitters, micro-sprayers, media filters, ventury injectors etc. He also discussed the design, installation, operation and field evaluation of micro-irrigation systems as per the Bureau of Indian Standards.

Assouline (2002) Studied and compared the effect of three emitter discharges, 0.25, 2.0, and $8.0 \mathrm{lph}$, on different aspects of the water 
regime in daily drip irrigated corn (Zea Mays L.), relying on field observations and numerical simulations. Field observations show that microdrip irrigation increase yield although this was not statistically significant under the experimental conditions and induces higher relative water content values in the $0.30 \mathrm{~m}$ depth layer, and lower ones in the $0.60 \mathrm{~m}$ to $0.90 \mathrm{~m}$ layer. A saturated zone below the emitter was obtained only for the 8.0 lph discharge. Comparing water content distributions with depth at the end of the application of the same amount of water close to the emitter, the driest profile is obtained for the lowest application rate. However, when compared at solar noon representing the time of the highest plant water demand, the upper $0.20 \mathrm{~m}$ layer of the soil irrigated at the lowest rate was the wettest.

Patel et al.,; (2003) developed a predication equation $(S=6.914+6.70 \mathrm{~T}+2.786 \mathrm{q})$ for determining the spacing between two adjacent laterals, $\mathrm{S}(\mathrm{cm})$ for a known operation duration, $\mathrm{T}$ (up to $3 \mathrm{hr}$ ) and emission rate of the laterals, q (ranging between 8 to $16 \mathrm{lph} / \mathrm{m}$ ) for closely spaced field crops. Widths of wetted strips under laterals having emission rates of $8,10,12$ and $16 \mathrm{lph} / \mathrm{m}$ were observed under durations of operation of 1, 2 and $3 \mathrm{hr}$, in a sandy loam soil. The wetted widths, in all the line sources were found increasing almost linearly with time as well as with increasing emission rates.

Saxena et al., (2004) conducted a field experiment in litchi, irrigated by drip and found that value of Christiansen's coefficient of uniformity remained close to 0.63 and 0.75 respectively, on emitters ' and plant basis when 4 drippers were employed per plant.

Provenzano et al., (2005) provided a procedure for evaluating total hydraulic head losses, including an extended local loss evaluation procedure, and a simplified procedure based on the assumption of constant outlet discharge. The results showed a $2.4 \%$ error when compared with total head loss measurements on 15 commercially available drip irrigation laterals. One difficulty in drip irrigation lateral hydraulics is in determining a correct estimation of the friction factor, $f$, as used in the DarcyWeisbach equation to determine hydraulic head loss in the lateral. This difficulty arises because of $f$ along the lateral due to changes in discharge with respect to location.

Shete (2005) reported reasons for variable $\mathrm{f}$ values (Darcy-Weisbach) for laterals with different diameters, shapes, length, numbers of outlets and the discharge. The $f$ values for laterals of $12 \mathrm{~mm}$ to $25 \mathrm{~mm}$ diameters were reported for number of outlets varying one to 500.

Kumar et al., (2007) conducted a study to evaluate the hydraulic performance of drip irrigation system with four emission devices viz dripper, micro-tube, drip-in and drip tape. At a particular spacing, the uniformity coefficient and emission uniformity increased while coefficient of variation decreased as the operating pressure head increased for all emission devices. The coefficient of manufacturing variation was lowest for micro-tubes and highest for drip tape. The Suitability/unsuitability of different emission devices was discussed. The microtube was not suitable for close spacing.

Yildirim (2007) proposed a simple method for the hydraulic design of trickle laterals and showed that in some cases when the local hydraulic losses were ignored, the system designs had significant error.

Guohua et al., (2009) carried out a field experiment and found that profile root distribution pattern changed with irrigation methods. Soil profile water uptake was 
correlated to the root system and soil water dynamics. Due to the appropriate soil water and higher root density in the surface soil layer under sprinkler and surface drip irrigation, the main water uptake zone was concentrated in the upper layer and under border irrigation, water uptake in $50 \mathrm{~cm}$ to $100 \mathrm{~cm}$ depth was stimulated, which caused the main uptake zone downward.

Siag et al., (2010) studied the impact of different spacing of surface drip lines and irrigation levels (0.6, 0.8 and 1.0 PET) on cotton growth and yield. The results revealed that cotton yield and water use efficiency (WUE) under drip was significantly higher than conventional flood irrigation.

Maximum yield was achieved under drip line for each row of crop with irrigation level of 0.8 PET, whereas WUE was recorded for the same drip line spacing, but at 0.6 PET irrigation levels. The initial growth (as reflected by leaf area index) was retarded for drip line in between two rows of crop as compared to drip line for each row of crop, but the rate of growth were similar for all drip line spacing after 45 days of sowing.

Kassab et al., (2012) indicated that decreasing the amount of irrigation water significantly reduced plant height, number of green leaves per plant, head diameter and total dry matter per plant of sunflower. The same tendency was observed for yield and its components. Also, it decreased significantly seed oil content. But a reverse trend could be detected concerning water use efficiency. Significant differences were observed between the two studied sunflower cultivars with respect to growth, yield and its components as well as water use efficiency. Furthermore, there was no significant interaction between the two studied factors regarding all studied growth, yield and its components, oil content as well as water use efficiency.
Lodhi et al., (2014) conducted a field experiment with three IW/CPE ratio of 0.60 , 0.75 and 0.90 under drip irrigation and found significant effects of irrigation on leaf area index, plant height, dry matter accumulation, number of days to flowering, fruit initiation, fruit maturity, fruit girth, number of fruit per plant, fruit length, yield and WUE. Best drip irrigated treatment IW/CPE ratio of 0.75 gave an increase of $30.67 \%$ over furrow irrigation with paired row planting and an increase of $33.74 \%$ over furrow irrigation with single row planting. The per cent of water saving for drip irrigation treatment IW/CPE ratio of 0.60 , 0.75 and 0.90 were $51.01 \%, 39.72 \%$ and $28.73 \%$ respectively over the furrow irrigation treatment. Irrigation treatment IW/CPE ratio of 0.75 gives maximum yield and highest WUE.

\section{Pressure losses in drip irrigation}

The estimation of pressure loss along the length of a drip line was derived in a form of simple differential equation by $\mathrm{Wu}$ and Gitlin (1974), while Keller and Karmeli (1974) devised an equation that was of the power form for the emitter characteristics.

Christiansen (1942) proposed a simple and accurate method for finding the friction losses for pipeline with multiple outlets. This method can also be applied for laterals with distributors. The method includes estimation of friction loss in the line assuming that all the water is carried to the end of the line and multiplying this by a loss factor. The loss factor is a dependent of number of outlets on the line and the type of equation used. To accurately evaluate friction head losses along the laterals, both friction losses and local losses due to the presence of emitters in pipes must be considered.

$\mathrm{Wu}$ (1975) explained the energy gradient lines for different field situations. $\mathrm{He}$ 
suggested that straight energy line can be used to design mainlines for drip irrigation system. He reported that the optimal slope of the energy gradient line is determined as a curve little bit below the straight energy gradient line.

Bezdek and Solomon (1978) have shown that the Darcy's-Weisbach equation is a more accurate basis for calculating head losses in a smaller diameter drip laterals than HazenWilliam's equation. This is reasonable because Hazen-Williams equation fails to account for high Reynolds number and relatively inaccurate for low velocity or small diameters. Extreme locations in the lateral and sub main suggested by Merriam and Keller (1978) provided useful information on head losses in laterals and sub main. Gillespie et al., (1979) showed that the kinetic energy is considered to be small and neglected to a drip irrigation line.

$\mathrm{Wu}$ and Gitlin (1979) reported that the pressure variation along a lateral line can be determined by linear combination of energy drop by friction and energy gain /loss by either uniform or non-uniform slope.

Anyoji and Wu (1987) developed a technique using a statistical approach. Using Taylor's theories, mean emitter flow could be derived by considering the pressure head and proportionality constant $\mathrm{k}$ in the emitter equation $\mathrm{q}=\mathrm{khx}$, as two random variables. The coefficient of variation of pressure head was statistically determined from the average and variance of pressure head which was affected by friction and slope changes along the lateral line. Based on the coefficient of variation of pressure head along a lateral line and the variation of emitter flow caused by manufacturers.

Hathoot et al., (1993) estimated the friction head loss between successive emitters by the
Darcy-Weisbach formula, taking into account the variation of the Reynolds number, the different zones on Moody diagram and the friction coefficient formula corresponding to each zone.

Scaloppi and Allen (1993) derived several mathematical relations for computing maximum, minimum and average pressure heads and their locations of occurrence along a lateral. When compared to pressure and locations of occurrence computed using a discredited, stepwise computation procedure, values computed using the developed equations were generally within $5 \%$ for the locations of occurrence.

Kang and Nishiyama (1994) developed a simple method for hydraulic analysis of sub main unit. The lateral discharge equation was used to express the relationship between the inlet discharge and the inlet pressure head of a lateral.

Manisha et al., (2015) studies the hydraulic performance of drip irrigation system under different operating pressure. Result shows that the discharge flow rate of emitter is increased when the increase of the pressure and the coefficient of variation is increased when the pressure is decreased means the pressure directly affected the discharge rate of emitter. The average emission uniformity coefficient observed at 1.5, 1.2, 0.9 and $0.7 \mathrm{~kg}$ $/ \mathrm{cm} 2$ pressure was 95.04, 95.95, 94.44 and 87.63 percent respectively for $4 \mathrm{lph}$. It is clear from that emission uniformity at $1.2 \mathrm{~kg} / \mathrm{cm} 2$ operating pressure.

\section{Economic of drip irrigation}

One of the major issues usually raised by the farmers about this drip irrigation is its economic viability. This arises of the fact that drip irrigation is capital intensive technology. The economic chart developed by Keller 
(1965) could be used in the selection of the most economical pipe size for a given set of economic parameters.

Al-Amoud (1996) developed formulae to estimate pressure drop in hoses with connected emitters based on the DarcyWeisbach and Hazen-Williams equations. Based on the statistical analysis of the data, empirical formulae were developed for plastic pipes and for emitters.

Bagarello et al., (1997) carried out an experimental investigation to evaluate local losses due to the protrusion of emitter barbs into the flow in drip irrigation lines. Local losses to different emitter systems were measured for different Reynolds numbers and carried out an experimental investigation to deduce an evaluating procedure of local losses due to protrusion of emitter barb into the flow in drip irrigation lines. Local losses corresponding to different pipe online emitter systems were measured for different Reynolds number values.The various friction factors were evaluated. Hazen Williams and DarcyWeisbach friction factor, " $\mathrm{f}$,,were found to be 112.8 and 0.593 respectively and Fanning's $(\mathrm{Ff})$ and Blassius $(\mathrm{Fb})$ friction factors were 0.0374 and 0.0367 respectively. The uniformity values were computed by Christiansen, Wilcox and Keller-Karmelli formulae. The values of emission uniformity computed by Keller- Karmelli were logical and ranged from 96 to $98 \%$.

Reddy et al., (2000) evaluated pressure variation in the pipelines using a modified form of Bernoulli's equation. Head loss due to friction was evaluated by Darcy- Weisbach equation. They reported that it is better to opt for an economical design with varying pipe sizes for main lines rather than a design with uniform pipe size or higher uniformity. It is possible to save up to 29 per cent on the total annual cost over the criteria where the emission uniformity was the lone parameter in designing the system.

Robert (2000) studied on the economic comparison of drip irrigation $v s$ furrow irrigation and found that drip irrigated crop production has $25 \%$ higher yields, $18 \%$ lower chemical costs, $26 \%$ lower fertilizer costs, $47 \%$ higher capital costs, $19 \%$ higher fixed costs, and $20 \%$ lower seed costs and concluded that drip irrigation produced a $12 \%$ greater net operating profit than furrow irrigation.

Wang et al., (2000) conducted a study on emitter flow to improve emitter performance. The Galerkia penalty finite element method was applied to simulate the field in the emitter. At different flow characteristics, the influence of Reynolds number on the flow field in typical emitters was analyzed. A new equation for calculating the coefficient and rate of discharge was developed using a nominal simulation.

Vallesquina and Luque- Escamilla (2001) presented a new approach for solving lateral hydraulic problems in laminar or turbulent flow. The outflow was treated as a discrete variable event by means of Taylor polynomials used to calculate flow rates along the lateral. The friction head loss was calculated using the Darcy-Weisbach equation with a non-constant logarithmic friction factor.

Pedro et al., (2001). A new approach for showing lateral hydraulic problems in laminar or turbulent flow was evaluated. The outflow is treated as discrete variable event by means of Taylor polynomial used to calculate flow rates along the lateral.

Narayanamoorthy (2003) net income which is the difference between gross income and total cost of cultivation, explain the profit level of 
drip irrigation and furrow irrigation method. Since drip irrigation increases the productivity with reduced cost of cultivation, the net income under drip irrigation is substantially higher than that of crops under furrow irrigation. The three general categories of optimization technique for pipe networks were graphical technique, analytical technique and simulation technique. Among these three techniques, analytical technique was the most widely used technique. Good examples of application of analytical techniques were the linear programming methodology based procedures for the optimization of pipe networks.

Ramesh (2003) investment decision for shifting to drip irrigation will depend upon many factors; including cost of cultivation, productivity, yield gain factor, cost of produce, electricity charges, depth of groundwater and irrigation requirement. These parameters vary from crop to crop, place to place, size of plot and farmer to farmer. Therefore, a sweeping recommendation suitable for all conditions cannot be made. In view of this, a software program has been developed for estimating the threshold economic value of the investment cost of drip irrigation. In addition to the threshold value of investment cost, the software provides information on energy consumption and net return. The software can be used both for annual crops such as sugarcane or seasonal crops such as vegetable rotations (winter-summer).

Saini et al., (2006) evaluated drip irrigation system for different crop sequences, which consist of vegetable crop sequence, vegetable and field crop sequence and only field crop sequence and found that drip irrigation method gave substantially higher net returns for vegetable crop sequence, because water saved with drip irrigation method can be used to irrigate the additional area. The net return with drip was 3.6 times higher as compared to conventional Irrigation method. Other crop sequences with drip irrigation method also gave nearly equivalent net return as compared to conventional method of irrigation.

Abdelraouf et al., (2011) carried out an field experiment and found that there were no significant difference between the highest values of net income under drip line spacing at $15 \mathrm{~cm}, 25 \mathrm{~cm}$ and $35 \mathrm{~cm}$ and sprinkler irrigation and considering economical view they recommended the value under $35 \mathrm{~cm}$ drip line spacing 7587(L.E./ ha) in addition to saving $10 \%$ from irrigation water compared with sprinkler irrigation system.

Kaushal et al., (2011) evaluated benefit-cost ratio without subsidy and with subsidy on drip irrigation and found that the treatment combination of drip irrigation under IW/CPE ratio 0.75 with $45 \mathrm{~cm}$ tunnel height gave highest benefit cost ratio (2.93 without subsidy) and (3.05 with maximum subsidy) on drip irrigation. He also found significant effect of irrigation, tunnel height on sweet pepper yield and their interaction was also significant.

Himanshu et al., (2012) evaluated the effect of irrigation levels $(25,75,125,175$ and $225 \%$ of pan evaporation replenishment) and lateral spacing $(0.5 \mathrm{~m}$ and $1.0 \mathrm{~m})$ and found highest mean marketable yield of cabbage (90.51 t/ha) when irrigation was applied at $175 \%$ of pan evaporation replenishment with $1.0 \mathrm{~m}$ lateral spacing due to the higher mean head weight $(2.26 \mathrm{~kg})$. A further increase in irrigation amount resulting from $225 \%$ of pan evaporation replenishment reduces the marketable yield significantly due to significant reduction in mean head weight $(2.15 \mathrm{~kg})$. Irrigation at $25 \%$ of pan evaporation replenishment gave the higher irrigation production efficiency $(61.59 \mathrm{~kg} / \mathrm{m} 3)$ with $1.0 \mathrm{~m}$ lateral spacing. It decreases 
significantly with increase in irrigation level. Minimum irrigation production efficiency was recorded with $225 \%$ of pan evaporation replenishment $(13.36 \mathrm{~kg} / \mathrm{m} 3)$ with $0.5 \mathrm{~m}$ lateral spacing because it increases seasonal water applied considerably but decreases the marketable yield. Irrigation at $175 \%$ of pan evaporation replenishment and $1.0 \mathrm{~m}$ lateral spacing resulted in higher gross return (271530 Rs/ha), net return (210972 Rs/ha) and benefit cost ratio (4.48). In spite of high initial investment, drip irrigation method is highly profitable for cabbage production with $1.0 \mathrm{~m}$ lateral spacing.

Study of hydraulic performance of drip irrigation system will be helpful for deciding Operating pressure, lateral, emitter and plant spacing along with duration of irrigation through an emitter of known discharge. Adoptability of drip irrigation gives higher production with minimum cost. It was found that all farmers at least doubled their irrigated area and reduced labour by half. In India, with water often pumped from deep tube wells, introduction of the low cost drip system showed promising results.

\section{Acknowledgement}

The author expressed his deep sense of gratitude to Dr. S.K. Pyasi, Professor Department Soil and Water Engineering, CAE, JNKVV, Jabalpur, Madhya Pradesh and Dr. Bal Krishna, Sr. Manager/Principle Scientist, Jain R\&D Laboratory, Jain Irrigation Systems Ltd Agripark, Jain Hills, Jalgaon for his valuable guidance, keen interest and encouragement rendered during the course of this study.

\section{References}

Abdelraouf RE., Refaie KM., Hegab IA. 2011. Effect Of Drip Lines Spacing And Adding Compost On The Yield And Irrigation Water Use Efficiency Of
Wheat Grown Under Sandy Soil Conditions. Journal of Applied Sciences Research, 9(2): 1116-1125

Alamoud A.I., 1996. Analysis of pressure drop due to emitter in trickle irrigation lateral connections. Bulletin of Faculty of Agriculture, University of Cairo, 47(2):213-234

Anonymous, 2017. Horticultural Statistics at a Glance 2017, Visit us at: www.agricoop.nic.in, pg.no.151.

Anyoji H., and I.P. Wu. 1987. Statistical approach for drip lateral design. Transaction of ASAE. Vol-30(1):187-192

Assouline S., 2002. The Effects of Micro drip and Conventional Drip Irrigation on Water Distribution and Uptake. Soil Science Soc. Am. Journals 66:1630-1636 (2002).

Bagarello V., Ferro V, Provenzano and D. Pumo. 1997. International Journal of the Irrigation and Drainage Engineering, 123: $1-7$

Baouan J., and $\mathrm{Xu}$ Yingain.1998. The Conception of the eco-environment water demand \& its classification in arid land, Xinjiang Institute of Geography, Chinese academy of Science, Urumqi, www.cnki.com.cn, China.

Bezdek J.C., and Solomon K. 1978. Approximating Friction factors for Trickle Tubing. Journal of Irrigation and Drainage, Division, ASCE, Vol. 104, No. IR. 4.

Camp, C.R., E. J. Sadler, and W.J. Busscher, 1989. Subsurface and alternate -middle micro irrigation for the Southeastern Coastal Plain. Transactions of ASAE, 32(2): 451-456.

Christiansen J.E., 1942. Hydraulics of sprinkling systems for irrigation. ASCE, 107:221-239.

Decroix, M and A. Malaval. 1985. Laboratory evaluation of trickle irrigation equipment for field system design. Proceedings of the third International Drip/Trickle Irrigation Congress, Volume I, California, USA. pp. 325-338. 
Deshmukh M., Sinha Jand and Tripathi M.P. (2015). Studies the hydraulic performance of drip irrigation system under different operating pressure. International Journal of Applied Engineering and Technology, http://www.cibtech.org/jet .htm 2015 Vol. 5 (2) April-June, pp.58-63.

Guohua L., Yaohu K. and Lan L. 2009. Effect of irrigation methods on root development and profile soil water uptake in winter wheat. Irrigation Science (2010) 28:387-398.

Hathoot M., Al Amoud. I., and S. Mohammed. 1993. International Journal of the Irrigation and Drainage Engineering, 119(5): 756-767.

Jadhaw S. S., G. B. Gutal and A. A. Chougule. 1990. Cost economies of the drip irrigation system for tomatoes crop. Department of Agricultural Engineering, College of Agriculture, Pune, India.

Kadam J. R., 1993. Evaluation of different irrigation methods for growth and yield of tomatoes. Annals Plant Physio, 7: 7884.

Kang Y., and Nishiyama. 1994. Hydraulic analysis of micro irrigation sub main units. Transactions of the ASAE, 38(5): 1377-1384.

Kassab O.M., Abo AA., and Abo M.S.A. 2012. Water Use Efficiency and Productivity of Two Sunflower Cultivars As Influenced By Three Rates of Drip Irrigation Water. Journal of Applied Sciences Research, 8(7): 3524-3529, 2012.

Keller J., 1965. Selection of economical pipe size for sprinkler irrigation systems. Transactions of ASAE 8(2):186-190.

Keller J., and Karmeli D. 1974. Trickle irrigation design parameters. Transactions of the American Society of Agricultural Engineers. 17 (4):678-84.

Kumar S., and Singh P. 2007. Evaluation of Hydraulic Performance of Drip Irrigation System. Indian Journals of Agricultural Engineering.Vol 44, No 2 (2007).

Lodhi A.S., Kaushal A., Singh K.G. (2014). Impact of irrigation regimes and low tunnel height on microclimatic parameters in the growing of sweet pepper. Indian Journal of Science and Technology, Vol 7(6), 790-794, June 2014. Narayanamoorthy A. 2003. Averting Water Crisis by Drip Method of Irrigation: A Study of Two WaterIntensive Crops", Indian Journal of Agricultural Economics, Vol. 58, No. 3, July-September, pp. 427-437.

Merriam J.L., and Keller J. 1978. Farm Irrigation System Evaluation: A Guide for Management. Utah State University.

Patel N., Rajput TBS., 2003. Line Source of Water Application - An Appropriate Drip Irrigation System for Field Crops. Indian Journals of Agricultural Engineering. Vol 40, No 2 (2003).

Pedro V.P., and Pedro L.L. 2001. New algorithm for hydraulic calculation in irrigation laterals. Journal of Irrigation and Drainage Engineering, 127(4): 254260

Provenzano G., Pumo D., Dio P Di. 2005. Simplified procedure to evaluate head losses in drip irrigation laterals. Journal of Irrigation and Drainage Engineering (ASCE), 131(6), 525-532, doi: 10.1061/(ASCE)07339437(2005)131:6(525)

Ramesh 2003. Investment decision model for drip irrigation system, Irrigation Science 22:79-85

Reddy K.Y., Tiwari K.N., and Ravindra V. 2000. Hydraulic analysis of trickle irrigation system for economic design. International Agriculture Engineering Journal, 9(2): 81-95.

Saxena C.K., and Gupta S.K. 2004. Drip Irrigation for Water Conservation and Saline / Sodic Environments in India: A Review. Natural Resources Engineering and Management and AgroEnvironmental Engineering. Proceedings of International Conference on Emerging Technologies in Agricultural and Food Engineering (etae 2004). Indian Institute of Technology, Kharagpur, India December 14-17,2004. Anamaya 
Publishers, New Delhi, 110 030, India. Pp 234-24.

Scaloppi, E. J., and Allen, R. G. 1993. Hydraulics of irrigation laterals: Comparative analysis. J. Irrig. and Drain. Engrg., ASCE 119(1): 91-115.

Shete D.T., 2005. Determining f factors for laterals in micro irrigation. In: Choudhary ML., Chandra P. and Mishra P. (Eds.) Proceedings of International conference on Plasticulture and Precision Farming, held during November 17-21, 2005 at New Delhi. Pp. 91-97.

Siag M., Kaushal M.P., and Buttar G.S. 2010. Impact of Drip line Spacing on Cotton Growth and Yield. Indian Journals of Agricultural Engineering. Vol 47, No 4 (2010).

Singh S.K., 1999. Standardization of materials and quality parameters of micro-irrigation systems. Proceedings of the National Seminar on Problems and Prospects of Micro-Irrigation - A Critical Appraisal, Bangalore, Nov 19-20, 1999. Institution of Engineers (India): 107-114.

Tekinel, O., R. Kanber, S. Onder, N. Baytorun and R. Bastug. 1989. The effects of trickle and conventional irrigation methods on some crop yields and water use efficiency under Cukurova conditions. Irrigation: theory and practice, pp. 641-651, Southampton, UK.

Vallesquino and L. Luque- Escamilla. 2001. Food and agriculture organization of the United Nations. Journal of the Irrigation and Drainage Engineering, Vol. 127, No.4, pp.254-260

Wang S.X., Liu G.X., and G. Baoan. 2000. Flow characteristics in labyrinth emitter used for agricultural irrigation. Transactions of the Chinese Society of Agricultural Engineering, 16 (4): 61-63

Watters A.W., and Keller J. 1978. Trickle irrigation tubing hydraulics. ASAE Paper No. 78- 2015, American Society of Agricultural Engineers, St. Joseph. Michigan, USA

Wei Z., Tang Y., W. Zhao and B. Lu. 2003. Rapid development technique for drip irrigation emitters. Rapid Prototyping Journal, 9: 104-110.

Wu I.P., 1975. Journal of the Irrigation and Drainage Division, Vol. 105, No.2, pp.231-243.

Wu I.P., and Gitlin H.M. 1974. Drip irrigation based on uniformity. ASAE, 3/429-432.

Wu I.P., and Gitlin H.M. 1975. Energy gradient lines for drip irrigation laterals. ASCE. Journal of Irrigation and Drainage Engineering. 101 (IR4): 321-326.

Wu I.P., and M. Gitlin. 1979. Journal of the Irrigation and Drainage Division,

Youngs E.G., P.B. Leeds-Harrison and A. Alghusni. 1999. Surface pounding of coarse-textured soils under irrigation with a line of surface emitters. J. Agric. Eng. Res., 73: 95-100.

\section{How to cite this article:}

Satyendra Thakur, S.K. Pyasi, B.K. Yadav, R.N. Shrivastava, S.K. Sharma and Singh, R.B. 2018. Hydraulic Performance of Drip Irrigation in Tomato - A Review. Int.J.Curr.Microbiol.App.Sci. 7(05): 2109-2118. doi: https://doi.org/10.20546/ijcmas.2018.705.246 